\title{
Anion amphiprotic ionic liquids as protic electrolyte matrices allowing sodium metal plating
}

\author{
Jankowski, Piotr; Matuszek, Karolina ; Treskow, Marcel ; Armand, Michel ; MacFarlane, Douglas ; \\ Johansson, Patrik
}

Published in:

Chemical Communications

Link to article, DOI:

10.1039/c9cc06083a

Publication date:

2019

Document Version

Peer reviewed version

Link back to DTU Orbit

Citation (APA):

Jankowski, P., Matuszek, K., Treskow, M., Armand, M., MacFarlane, D., \& Johansson, P. (2019). Anion amphiprotic ionic liquids as protic electrolyte matrices allowing sodium metal plating. Chemical Communications, 55(83), 12523-12526. https://doi.org/10.1039/c9cc06083a

\section{General rights}

Copyright and moral rights for the publications made accessible in the public portal are retained by the authors and/or other copyright owners and it is a condition of accessing publications that users recognise and abide by the legal requirements associated with these rights.

- Users may download and print one copy of any publication from the public portal for the purpose of private study or research.

- You may not further distribute the material or use it for any profit-making activity or commercial gain

- You may freely distribute the URL identifying the publication in the public portal 


\section{Anion Amphiprotic Ionic Liquids as Protic Electrolyte Matrices Allowing Sodium Metal Plating}

Received 00th January 20xx, Accepted 00th January 20xx

\author{
Piotr Jankowski, ${ }^{\text {a,b, }, \mathrm{c}}$ Karolina Matuszek, ${ }^{\mathrm{d}}$ Marcel Treskow, ${ }^{\mathrm{a}, \mathrm{e}}$ Michel Armand, ${ }^{\mathrm{f}}$ Douglas \\ MacFarlane ${ }^{d}$ and Patrik Johansson ${ }^{\mathrm{a}, \mathrm{g}}$
}

DOI: $10.1039 / \times 0 \times x 00000 x$

The sodium-ion battery (SIB) is proposed as a complementary technology to today's commercially dominant lithium-ion battery (LIB). While much know-how can be transferred from LIBs to SIBs, adjustments are still necessary, not the least for the electrolytes employed. Here the use of anion amphiprotic ionic liquid (AAIL) based electrolytes is proposed for SIB application. Two different AAILs, based on organic trifluoromethylsulfonylamide (TFSAm) and inorganic $\mathrm{HSO}_{4}^{-}$anions, respectively, doped with $\mathrm{NaTFSI}$ salt have been studied, focusing on electrochemical stability and transport properties, complemented by studies of the ion-ion interactions, and final sodium-ion battery performance via stripping/plating vs. sodium metal electrodes.

The last three decades the lithium-ion battery (LIB) technology has risen in popularity to the point that today it totally dominates the market for modern rechargeable batteries, being used for portable electronics, electric cars and grid storage. ${ }^{1-5}$ However, continuing with lithium based technologies might not be the best solution for the future. The relatively limited resources of lithium and uneven global distribution cause high cost, large price fluctuations of the raw material and a dependency on a few countries willingness to share their natural resources. ${ }^{6-8}$ Therefore, development of complementary battery technologies to the LIB is crucial. Among the possibilities, sodium can be considered as a natural candidate to replace lithium, since these two elements are chemically very similar, paving the way for sodium-ion batteries (SIBs) ${ }^{9-12}$

The non-aqueous electrolytes, necessary for SIB batteries, can be based on matrices of organic solvents ${ }^{13-15}$, polymers ${ }^{16,17}$ or ionic liquids (ILs) ${ }^{18,19}$. All have different advantages and

a. Chalmers University of Technology, Department of Physics, Gothenburg, Sweden b. Technical University of Denmark, Department of Energy Conversion and Storage, Kgs. Lyngby, Denmark

c. Warsaw University of Technology, Faculty of Chemistry, 00-664 Warsaw, Poland

d. Monash University, School of Chemistry, Clayton, Victoria, Australia

e. Evonik R\&D, Frankfurt am Main, Germany

f. CIC Energigune, 01510 Miñano, Spain

g. Alistore-European Research Institute, CNRS FR 3104, Hub de l'Energie, Amiens, France

Electronic Supplementary Information (ESI) available: experimental and computational details, spectroscopic and computational analysis. See DOI: $10.1039 / x 0 x x 00000 x$ disadvantages. ILs and organic/IL hybrids in particular offer synergies between intrinsic safety and ion transport properties. ${ }^{20-23}$ Most attention has so far focused on aprotic ILs, due to their wider electrochemical stability windows, 24,25 although recently also protic ILs have been reported with similar transport properties, but different interactions. Importantly they also offer reduced charge transfer resistance for insertionextraction of charge carriers at the electrode/electrolyte interfaces for both LIBs and SIBs. ${ }^{26-28}$ The positive effect of the presence of a proton and its interactions have also been reported for modified anions; Armand et al. reported a less than fully fluorinated TFSI anion, i.e. $\left[\mathrm{N}\left(\mathrm{SO}_{2} \mathrm{CF}_{2} \mathrm{H}\right)_{2}\right]^{-}$, to be beneficial for the cation transport, especially in PEO based polymer electrolytes, by virtue of special hydrogen bonds created. ${ }^{29,30} \mathrm{All}$ this taken together turned our attention back to the concept of anion amphiprotic ILs (AAILs), which were originally designed as proton conducting materials for fuel cell application and distinguished by decoupled transport, ${ }^{31}$ and we now try to use them as electrolyte matrices for SIBs.

As 1-ethyl-3-methylimidazolium trifluoromethylsulfonylamide ([EMIm][TFSAm]) previously provided the highest conductivity, ${ }^{31}$ we have here used this AAIL and compare it with another more standard type of protic IL that analoguously has a proton in its anion structure: 1-ethyl-3-methylimidazolium hydrogen sulfate ([EMIm][HSO $\left.\mathrm{HS}_{4}\right]$, Fig. 1). Both AAILs were carefully dried to reach a water level $<45 \mathrm{ppm}$ and doped with sodium bis(trifluoromethanesulfonyl)imide (NaTFSI) to create SIB electrolytes.

We started our analysis with the pure ILs and found that the AAILs have superior transport properties, as illustrated by the Walden plot (Figure 2), allowing us to consider them as superionic ILs. ${ }^{32}$ The origin of this has been analysed before by us and was postulated to be related to a proton exchange equilibrium. ${ }^{31}$ Our present DFT calculations confirm the existence of this critical process, with the equilibrium shifted much more towards the singly-charged anion structure for

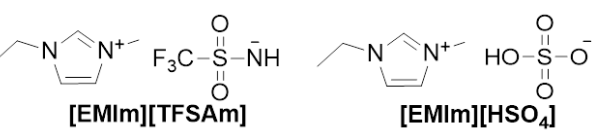

Figure 1. Chemical structures of the AAILs. 


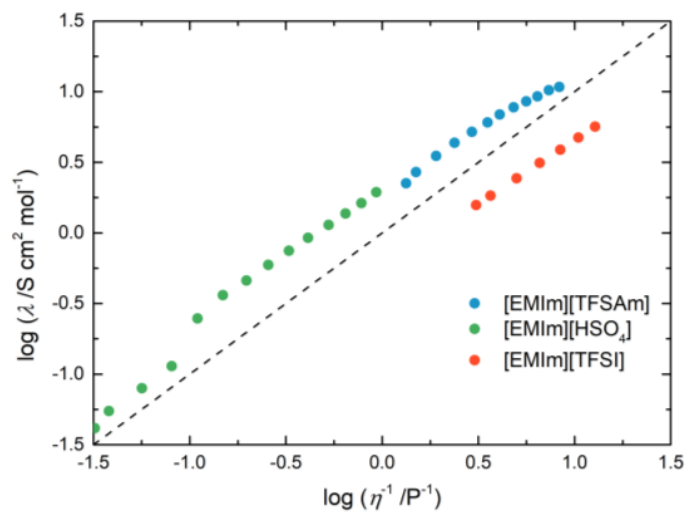

Figure 2. Walden plot of the studied ILs, with data for EMImTFSI from ref. 39

[TFSAm] $]^{-}$than for $\left[\mathrm{HSO}_{4}\right]^{-}$(Figure 3). This has a huge impact on the electrochemical stability; the singly protonated structures are predicted to have stabilities against reduction of -1.17 and $0.76 \mathrm{~V} v s$. $\mathrm{Na}^{+} / \mathrm{Na}^{\circ}$, respectively, while the doubly protonated structures are predicted to have poorer stabilities of 1.41 and $0.90 \mathrm{~V}$ vs. $\mathrm{Na}^{+} / \mathrm{Na}^{\circ}$, respectively, and the latter is for both structures related to the hydrogen evolution reaction (HER). Indeed, [EMIm] $\left[\mathrm{HSO}_{4}\right]$ exhibits the lower electrochemical stability and is reduced at ca. $1.0 \mathrm{~V}$ vs. $\mathrm{Na}^{+} / \mathrm{Na}^{\circ}$ (Figure 4), having a two orders of magnitude higher concentration of the doubly protonated form - as derived from the calculated equilibrium constants. To further test the stability, adding a small piece of sodium metal into this IL leads to formation of bubbles at the metal surface. The analogous test with the [EMIm][TFSAm] IL gives no bubble formation and the $\mathrm{CV}$ demonstrates stability at the potential of sodium metal, with a small process at $c a .1 \mathrm{~V}$ vs. $\mathrm{Na}^{+} / \mathrm{Na}^{\circ}$, possibly related to the formation of a passivation layer, similarly to that of highly concentrated electrolytes based on TFSI. ${ }^{33,34}$

Looking at the pure ILs, the lowest ion conductivity is observed for $[\mathrm{EMIm}]\left[\mathrm{HSO}_{4}\right]$ - around half order of magnitude lower likely primarily due to the much higher viscosity (Figure $5 \mathrm{a}$ ). In contrast, [EMIm][TFSAm] exhibits a similar ion conductivity as that reported for the "standard" [EMIm] [TFSI] IL. ${ }^{18}$ However, in Figure $5 \mathrm{a}$ there are different behaviours observed, likely related to different activation energies of the ion transport, and thus possibly different ion transport mechanisms. Doping of [EMIm][TFSAm] with NaTFSI causes a decrease in conductivity, connected with aggregation of the system, as observed for most $\mathrm{ILS}^{35}$ while for $[\mathrm{EMIm}]\left[\mathrm{HSO}_{4}\right]$ the introduction of NaTFS increases the conductivity. For both the NaTFSI doped AAILs a local maximum in ion conductivity is observed for $\mathrm{x}=0.15$ at 2.7 and $1.5 \mathrm{mS} \mathrm{cm}^{-1}$, respectively, corresponding to concentrations of ca. 0.7-0.9 mol kg-1 - quite typical of standard LIB (and SIB)

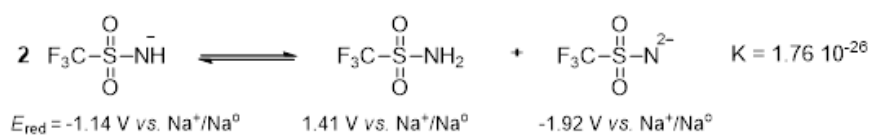

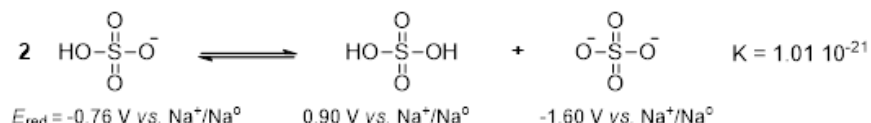

Figure 3. Proton exchange reactions in the AAILs; Equilibrium constants and reduction potentials obtained from DFT calculations.

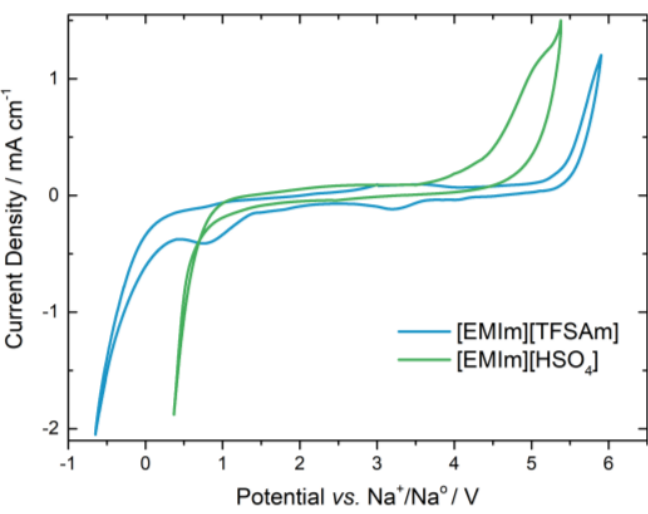

Figure 4. Electrochemical stability of the two AAILs. WE: Pt, RE: Ag, CE: SS. Potential of Ag calibrated vs. ferrocene, $\mathrm{E}_{\mathrm{Ag}}=-0.18 \mathrm{~V} \mathrm{vs}$. $\mathrm{Fc}^{+} / \mathrm{Fc}^{\circ}$

electrolytes. A further increase in salt concentration, into the highly concentrated electrolyte (HCE) regime, results in another two maxima in ion conductivity: at $4.0 \mathrm{mS} \mathrm{cm}^{-1}$ for $(\mathrm{NaTFSI})_{0.5}([\mathrm{EMIm}][\mathrm{TFSAm}])_{0.5}$ and $6.1 \mathrm{mS} \mathrm{cm}^{-1}$ for $(\mathrm{NaTFSI})_{0.4}\left([\mathrm{EMIm}]\left[\mathrm{HSO}_{4}\right]\right)_{0.6}$, respectively. At higher $\mathrm{NaTFSI}$ concentrations in $[\mathrm{EMIm}]\left[\mathrm{HSO}_{4}\right]$ a huge decrease in ion conductivity at lower temperatures is observed as the material partly crystallizes (melting point ca. $-20^{\circ} \mathrm{C}$, Figure S4). This also affects the glass transition temperature $\left(\mathrm{T}_{\mathrm{g}}\right)$ decreasing from $c a$. -65 to $-90{ }^{\circ} \mathrm{C}$. Much more of a glassy behaviour was recorded for the NaTFSI-[EMIm][TFSAm] system where no melting/crystallization is observed up to $\mathrm{x}=0.4$ and with a glass transition temperature more or less fixed at $c a .-72{ }^{\circ} \mathrm{C}$ (Figure S4). The appearance of crystalline phase $\left(T_{m}=160^{\circ} \mathrm{C}\right)$ for $x=0.5$ decreases $T_{\mathrm{g}}$ down to $-84{ }^{\circ} \mathrm{C}$, that also can explain the higher ion conductivity, while a further increase in NaTFSI concentration increases the $\mathrm{T}_{\mathrm{g}}$ to $-62{ }^{\circ} \mathrm{C}$, nicely correlated with a reduced ion conductivity.

Clearly the organic AAIL based system outperforms the inorganic for properties important for battery application. The $\left[\mathrm{HSO}_{4}\right]^{-}$based system indeed has some crucial drawbacks: low electrochemical stability, low ion conductivity, and ample crystallization, why only the TFSAm based system is targeted for SIBs. A detailed analysis show significant changes in the structure in this system upon salt addition (Supporting Information). Aggregation around $\mathrm{Na}^{+}$leads to the formation of a $\mathrm{Na}_{\mathrm{x}}$ TFSAm $\mathrm{y}$ phase, as seen also by DSC (Figure S4), together with a weaker intermolecular $\mathrm{H}$-bonding, related to an increasing competition with $\mathrm{Na}^{+}$coordination to the oxygen atoms of the anion (Figure S6). This is also confirmed by MD simulations, with a major contribution from TFSAm in the $\mathrm{Na}^{+}$ coordination and formation of densely packed $\mathrm{Na}_{\mathrm{x}} \mathrm{TFSAm}_{\mathrm{y}}$ clusters.

Finally, some plating/stripping tests in $\mathrm{Na} \mid \mathrm{Na}$ cells were performed for the electrolytes $\mathrm{X}_{\mathrm{NaTFSI}}=0.15$ and 0.5 at $60{ }^{\circ} \mathrm{C}$, a temperature used to compensate for the overall low ion conductivities (Figure 6). For the former electrolyte, the cycling was less stable, with significant potential increases during single cycles suggesting quite low sodium transference numbers, while the latter showed lower overpotentials that only slightly increased during subsequent cycles. This is a behaviour similar to other HCE IL based sodium conducting systems, where sodium conductivity has been inferred to occur through highly 

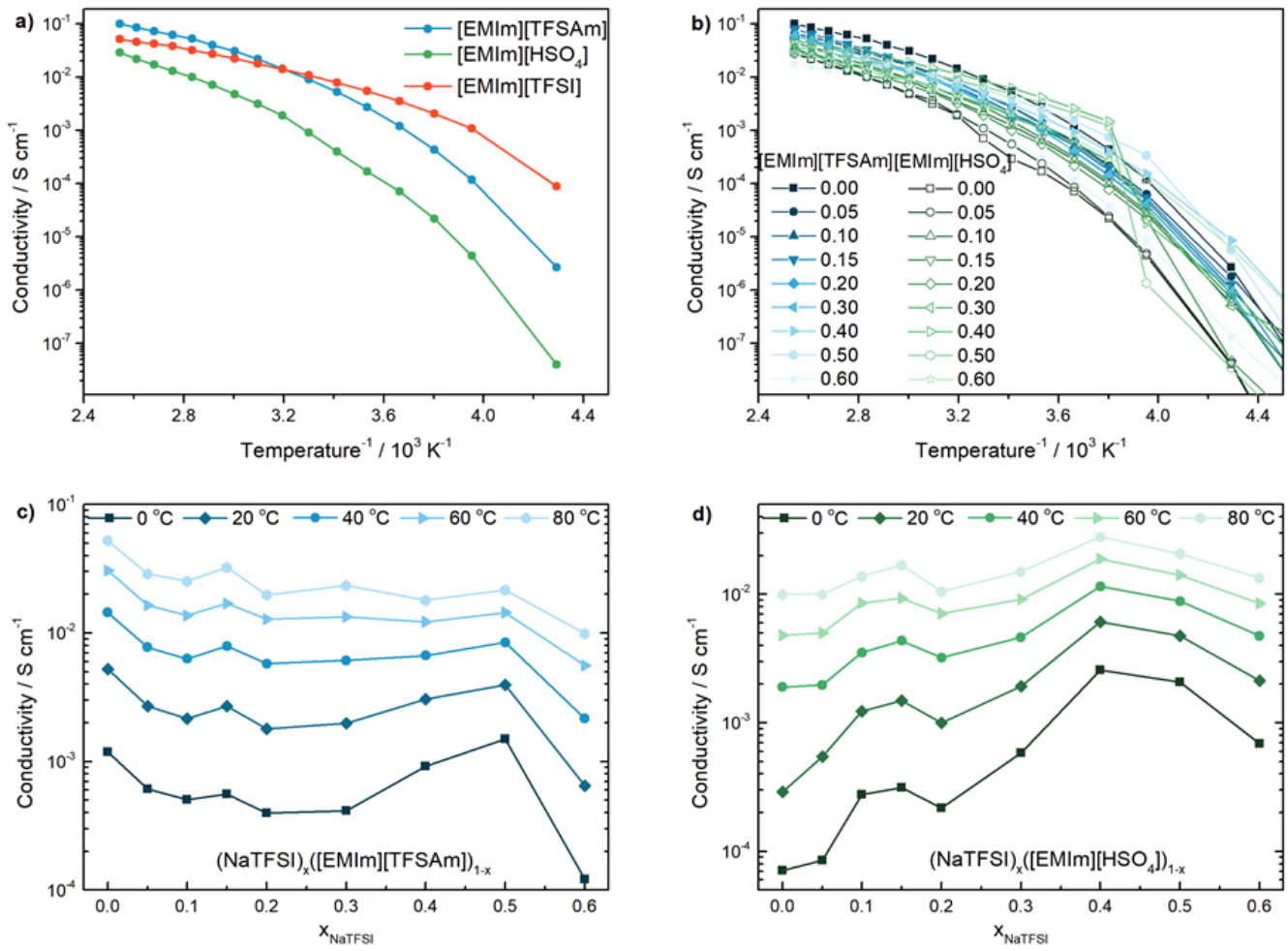

Figure 5. Conductivity curves for neat ILS (a), AAILs doped with NaTFSI (b), and corresponding isotherms for $(\mathrm{NaTFSI})_{x}([\mathrm{EMIm}][\mathrm{TFSAm}])_{1-\mathrm{x}}(\mathrm{c})$ and $(\mathrm{NaTFSI})_{\mathrm{x}}([\mathrm{EMIm}][\mathrm{HSO}])_{1-\mathrm{x}}(\mathrm{d})$. Data for EMImTFSI taken from ${ }^{18}$.

aggregated clusters. ${ }^{36-38}$ We speculate that the introduction of a proton in the anion structure may further support/facilitate this ion transport inside the cluster by a proton - sodium exchange at the basic oxygen centres enabling de-coordination of sodium and further improve the $\mathrm{Na}^{+}$mobility.

The results presented here show on possibilities for successful application of AAILs as matrices for Na-salts to create SIB electrolytes. The perhaps expected restricted diffusion of the relevant charge carrier and limited electrochemical stability window, due to $\mathrm{H}$-bonding related increases in viscosity and proton reduction directly at the anionic structure, were both shown to be overcome due to a unique amphiprotic anion design. The pure [EMIm][TFSAm] AAIL shows ample electrochemical stability together with adequate transport properties and moreover, after addition of NaTFSI the electrolyte contains sodium cation based aggregates, $\mathrm{Na}_{x} \mathrm{TFSAm}_{\mathrm{y}}$ clusters, as shown spectroscopically and supported

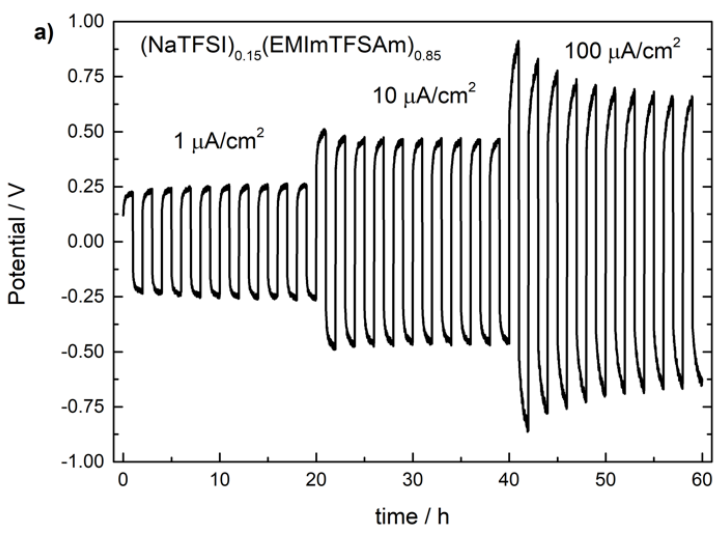

both by DFT and MD simulations. This results in high ion conductivity, as for other HCEs, especially for the equimolar mixture of [EMIm][TFSAm] and NaTFSI, which also provides acceptable sodium plating/stripping performance. Altogether this proves that the strategy to apply AAIL based battery electrolytes is promising and calls for further development and improvement.

\section{Acknowledgments}

All calculations were carried out at the Wrocław Centre for Networking and Supercomputing, Grant 346. The support by ALISTORE-ERI and Chalmers Area of Advance Energy to P. Jankowski are both gratefully acknowledged. P. Johansson acknowledges the financial support from the Swedish Energy Agency (contract \#37671-1, Next Generation Batteries) and

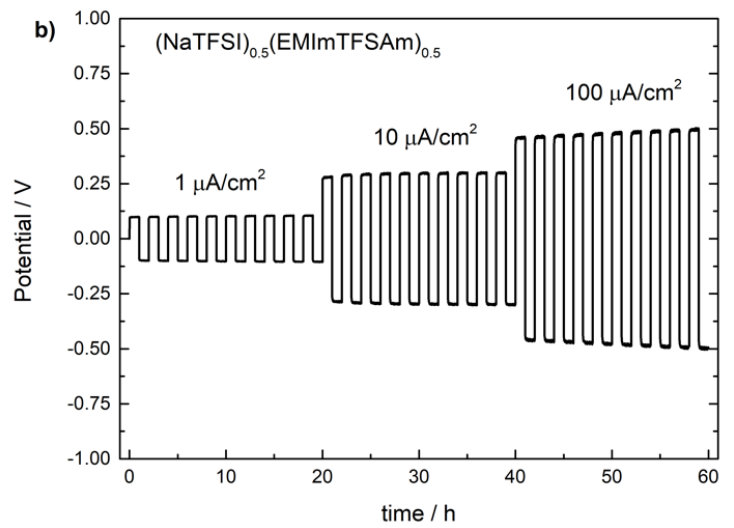

Figure 6. Na| Na cycling of $(\mathrm{NaTFSI})_{0.15}\left([\text { EMIm] [TFSAm] })_{0.85}\right.$ (a) and $(\mathrm{NaTFSI})_{0.5}\left([\mathrm{EMIm}][\text { TFSAm] })_{0.5}(\mathrm{~b})\right.$ at $60^{\circ} \mathrm{C}$. 
Chalmers Battery Initiative, part of the profile Materials for Energy Applications jointly managed by the Areas of Advance Materials Science and Energy at the Chalmers University of Technology. The stimulating discussions within the ALISTOREERI network are also highly appreciated. D. MacFarlane acknowledges the financial support of the Australian Research Council through the Australian Laureate Fellowship program.

\section{Conflicts of interest}

There are no conflicts to declare.

\section{Notes and references}

1 M. Winter, B. Barnett and K. Xu, Chem. Rev., 2018, 118, 1143311456.

2 D. Deng, Energy Science \& Engineering, 2015, 3, 385-418.

3 M. Li, J. Lu, Z. Chen and K. Amine, Advanced Materials, 2018, 30, 1800561.

4 B. Diouf and R. Pode, Renewable Energy, 2015, 76, 375-380.

5 G. E. Blomgren, J. Electrochem. Soc., 2017, 164, A5019-A5025.

6 M. Bini, D. Capsoni, S. Ferrari, E. Quartarone and P. Mustarelli, in Rechargeable Lithium Batteries, ed. A. A. Franco, Woodhead Publishing, 2015, pp. 1-17.

7 J.-M. Tarascon, Nature Chemistry, 2010, 2, 510.

8 C. Grosjean, P. H. Miranda, M. Perrin and P. Poggi, Renewable and Sustainable Energy Reviews, 2012, 16, 1735-1744.

9 C. Delmas, Advanced Energy Materials, 2018, 8, 1703137.

10 J.-Y. Hwang, S.-T. Myung and Y.-K. Sun, Chemical Society Reviews, 2017, 46, 3529-3614.

11 C. Vaalma, D. Buchholz, M. Weil and S. Passerini, Nature Reviews Materials, 2018, 3, 18013

12 K. Kubota and S. Komaba, J. Electrochem. Soc., 2015, 162 A2538-A2550.

13 A. Plewa-Marczewska, T. Trzeciak, A. Bitner, L. Niedzicki, M. Dranka, G. Z. Żukowska, M. Marcinek and W. Wieczorek, Chem. Mater., 2014, 26, 4908-4914.

14 A. Ponrouch, E. Marchante, M. Courty, J.-M. Tarascon and M. Rosa Palacín, Energy \& Environmental Science, 2012, 5, 85728583.

15 G. G. Eshetu, S. Grugeon, H. Kim, S. Jeong, L. Wu, G. Gachot, S. Laruelle, M. Armand and S. Passerini, ChemSusChem, 2016, 9, 462-471.

16 A. Bitner-Michalska, G. M. Nolis, G. Żukowska, A. Zalewska, M. Poterała, T. Trzeciak, M. Dranka, M. Kalita, P. Jankowski, L. Niedzicki, J. Zachara, M. Marcinek and W. Wieczorek, Scientific Reports, 2017, 7, 40036.

17 A. Boschin and P. Johansson, Electrochimica Acta, 2015, 175, 124-133.

18 D. Monti, E. Jónsson, M. R. Palacín and P. Johansson, Journal of Power Sources, 2014, 245, 630-636.

19 I. Hasa, S. Passerini and J. Hassoun, Journal of Power Sources, 2016, 303, 203-207.

20 S. Menne, R.-S. Kühnel and A. Balducci, Electrochimica Acta, 2013, 90, 641-648.

21 R.-S. Kühnel and A. Balducci, J. Phys. Chem. C, 2014, 118, 57425748.

22 C. V. Manohar, A. R. K, M. Kar, M. Forsyth, D. R. MacFarlane and S. Mitra, Sustainable Energy \& Fuels, 2018, 2, 566-576.
23 D. Monti, A. Ponrouch, M. R. Palacín and P. Johansson, Journal of Power Sources, 2016, 324, 712-721.

24 S. A. Mohd Noor, P. C. Howlett, D. R. MacFarlane and M. Forsyth, Electrochimica Acta, 2013, 114, 766-771.

25 D. Kundu, E. Talaie, V. Duffort and L. F. Nazar, Angewandte Chemie International Edition, 2015, 54, 3431-3448.

26 T. Vogl, S. Passerini and A. Balducci, Electrochemistry Communications, 2017, 78, 47-50.

27 T. Vogl, S. Menne, R.-S. Kühnel and A. Balducci, J. Mater. Chem. A, 2014, 2, 8258-8265.

28 T. Stettner, P. Huang, M. Goktas, P. Adelhelm and A. Balducci, J. Chem. Phys., 2018, 148, 193825.

29 H. Zhang, U. Oteo, H. Zhu, X. Judez, M. Martinez-Ibañez, I. Aldalur, E. Sanchez-Diez, C. Li, J. Carrasco, M. Forsyth and M. Armand, Angewandte Chemie, , DOI:10.1002/ange.201813700.

30 U. Oteo, M. Martinez-Ibañez, I. Aldalur, E. Sanchez-Diez, J. Carrasco, M. Armand and H. Zhang, ChemElectroChem, 2019, 6 1019-1022.

31 M. Treskow, J. Pitawala, S. Arenz, A. Matic and P. Johansson, J. Phys. Chem. Lett., 2012, 3, 2114-2119.

32 C. A. Angell, Y. Ansari and Z. Zhao, Faraday Discuss., 2011, 154 9-27.

33 N. Nakatani, K. Kishida and K. Nakagawa, J. Electrochem. Soc., 2018, 165, A1621-A1625.

34 L. Suo, O. Borodin, T. Gao, M. Olguin, J. Ho, X. Fan, C. Luo, C. Wang and K. Xu, Science, 2015, 350, 938-943.

35 H. Yoon, A. S. Best, M. Forsyth, D. R. MacFarlane and P. C. Howlett, Physical Chemistry Chemical Physics, 2015, 17 , 4656-4663.

36 F. Chen, P. Howlett and M. Forsyth, J. Phys. Chem. C, 2018, 122, 105-114.

37 A. Basile, F. Makhlooghiazad, R. Yunis, D. R. MacFarlane, M. Forsyth and P. C. Howlett, ChemElectroChem, 2017, 4, 986-991.

38 M. Forsyth, H. Yoon, F. Chen, H. Zhu, D. R. MacFarlane, M. Armand and P. C. Howlett, J. Phys. Chem. C, 2016, 120, 42764286.

39 C. Schreiner, S. Zugmann, R. Hartl and H. J. Gores, J. Chem. Eng. Data, 2010, 55, 1784-1788. 